\title{
Mechanism of Hard Agglomerate Formation in a High Purity Sub-micron $\alpha$-Alumina Powder
}

\author{
Chanel ISHIZAKI, ${ }^{\uparrow}$ Purwadi RAHARJO, ${ }^{\dagger \dagger}$ Kazunori SATO and Kozo ISHIZAKI \\ Nagaoka Gijutsu-Kagaku Daigaku (Nagaoka University of Technology), Nagaoka-shi, Niigata 940-2188
}

\author{
高純度サブミクロン $\alpha$ アルミナ粉の強固な凝集機構 \\ Chanel Ishizaki' · Purwadi Raharjo ${ }^{\dagger \dagger} \cdot$ 佐藤一則 · 石㟝幸三 \\ 長岡技術科学大学, 940-2188 新渴県長岡市
}

\begin{abstract}
A high purity, sub-micron, $\alpha$-alumina powder produced by the hydrolysis of aluminum alkoxide method and a thermally hydrated product of the as-received powder have been investigated. The powders were divided into two particle size range fractions. The intensity of aluminum trihydroxide polymorph bands is larger in the diffuse reflectance infrared Fourier transform (DRIFT) spectra of the large particle size fractions of the as-received, as well as the hydrated product. The amount of aluminum trihydroxide polymorphs in the hydrated powder was large enough to be detected in the X-ray diffraction (XRD) pattern of the powder. Scanning electron microscope (SEM) observation of the powders shows the presence of large agglomerates in the hydrated powder. A smaller amount of agglomerates is also noticeable in the as=received powder. Transmission electron microscope (TEM) images of the as-received and hydrated alumina powders revealed the presence of a surface layer interconnecting neighboring $\alpha$-alumina particles. It is concluded that $\mathrm{Al}(\mathrm{OH})_{3}$ surface structures of adjacent particles can form hydrogen bonding creating crystalline structures similar to the aluminum trihydroxide polymorphs. These structures are believed to be responsible for the formation of hard agglomerates even in the as-received alumina powder.
\end{abstract}

[Received June 16, 2000; Accepted October 11, 2000] Key-words : High purity sub-micron a-alumina, Surface hydration, Hard agglomerate formation mechanism, Aluminum
trihydroxide polymorphs

1. Introduction

Hydration or weathering effects on $\alpha-\mathrm{Al}_{2} \mathrm{O}_{3}$ powders usually is not taken into account during storage of the powder, since thermodynamically alpha phase of alumina has been considered as a stable phase. ${ }^{1)}$ Different from storage of non-oxide ceramic powders, e.g., AlN and $\mathrm{Si}_{3} \mathrm{~N}_{4}$ powders, which are usually kept in nitrogen purged glove boxes, the storage of alumina powder is just keeping the powder inside polyethylene bags. ${ }^{2)}$ The formation of hard agglomerates in alumina powders has been usually related to the presence of transition aluminas rather than the alpha phase itself.3),4) However, several theoretical as well as experimental studies concerning the interaction of water with $\alpha$-alumina surfaces have been reported. ${ }^{5}$-11) All the reports indicate that the dissociative path is favored resulting in a hydroxylated surface.

Hass et al. ${ }^{11)}$ simulated the chemistry of water on $\mathrm{Al}$ terminated (0001) $\alpha$-alumina surfaces with ab-initio Molecular Dynamics (MD). Their simulation results clearly established that, in the low coverage, $\mathrm{H}_{2} \mathrm{O}$ dissociation is kinetically as well as thermodynamically favorable on defect free $\alpha-\mathrm{Al}_{2} \mathrm{O}_{3}(0001)$ at room temperature. Simulations at higher $\mathrm{H}_{2} \mathrm{O}$ coverage showed that at least in the very early stages of reaction with $\mathrm{H}_{2} \mathrm{O}$, the unimolecular dissociation dynamics does not appear to be strongly perturbed by the presence of additional adsorbed molecules. They concluded that for a coverage of $10 \mathrm{OH}$ per square nanometer, complete hydroxylation of $\alpha-\mathrm{Al}_{2} \mathrm{O}_{3}(0001)$ would result in one $\mathrm{O}_{\text {ads }} \mathrm{H}\left(\mathrm{O}_{\text {ads }}\right.$,

\footnotetext{
† Permanent Address: Sinano Technology Corp., 20-6, Isurugiminami, Nagaoka-shi, Niigata 940-2117

現在：信濃テクノロジー，940-2117 長岡市石動南 20-6

† Present Address : ITAC Ltd., 1451, Jizoudou, Bunsui, Nishikanbara-gun, Niigata 959-0121

現在：ITAC, 959-0121 新潟県西蒲原郡分水地蔵堂 1451
}

water oxygen) on each surface $\mathrm{Al}\left(\mathrm{Al}_{\mathrm{s}}\right)$ and one $\mathrm{O}_{\mathrm{s}} \mathrm{H}\left(\mathrm{O}_{\mathrm{s}}\right.$, surface oxygen) for every three surface $\mathrm{O}\left(\mathrm{O}_{\mathrm{s}}\right)$ atoms. Considering the atoms $\left(9 \mathrm{Al}_{\mathrm{s}}, 27 \mathrm{O}_{\mathrm{s}}\right.$ and $\left.18 \mathrm{Al}_{\mathrm{i}}\right)$ involved in the single cell of the simulation, this may be written as:

$$
9 \mathrm{Al}_{\mathrm{s}}+9 \mathrm{O}_{\mathrm{s}}+9 \mathrm{O}_{\mathrm{ads}} \mathrm{HH}-9 \mathrm{Al}_{\mathrm{s}} \mathrm{O}_{\mathrm{ads}} \mathrm{H}+9 \mathrm{O}_{\mathrm{s}} \mathrm{H}
$$
At $\mathrm{OH}$ coverage $>10 \mathrm{OH}$ per square nanometer, many of the surface $\mathrm{Al}-\mathrm{O}_{\mathrm{s}}$ bonds were highly strained or broken, making some second-layer $\mathrm{Al}\left(\mathrm{Al}_{\mathrm{i}}\right)$ more accessible to $\mathrm{H}_{2} \mathrm{O}$. If all the second layer $\mathrm{Al}$ atoms of the cell become accessible, this further hydroxylation may be written as:

$$
18 \mathrm{Al}_{\mathrm{i}}+18 \mathrm{O}_{\mathrm{s}}+18 \mathrm{O}_{\mathrm{ads}} \mathrm{HH}-18 \mathrm{Al}_{\mathrm{i}} \mathrm{O}_{\mathrm{ads}} \mathrm{H}+18 \mathrm{O}_{\mathrm{s}} \mathrm{H}
$$

Adding the reaction products of Eqs. 1 and 2 the total hydroxylation may be written as:

$$
9 \mathrm{Al}_{\mathrm{s}} \mathrm{O}_{\text {ads }} \mathrm{H}+27 \mathrm{O}_{\mathrm{s}} \mathrm{H}+18 \mathrm{Al}_{\mathrm{i}} \mathrm{O}_{\text {ads }} \mathrm{H}
$$

Further $\mathrm{MD}$ simulations showed that an interesting rearrangement can occur: The interior $\mathrm{O}_{\text {ads }} \mathrm{H}$ replaces its neighboring $\mathrm{O}_{\mathrm{s}} \mathrm{H}$, whereas the $\mathrm{O}_{\mathrm{s}} \mathrm{H}$ tilts up and becomes singly coordinated to a surface $\mathrm{Al}$, providing a mechanism for the interchange of $\mathrm{O}_{\mathrm{s}}$ and $\mathrm{O}_{\text {ads }}$ and an evidence for incipient $\mathrm{Al}(\mathrm{OH})_{3}$ formation on the surface. Taking into consideration this rearrangement, Eq. (3) can be rewritten as:

$$
9 \mathrm{Al}_{\mathrm{s}}\left(\mathrm{O}_{\mathrm{ads}} \mathrm{H}\right)\left(\mathrm{O}_{\mathrm{s}} \mathrm{H}\right)\left(\mathrm{O}_{\mathrm{s}} \mathrm{H}\right)+9 \mathrm{O}_{\mathrm{s}} \mathrm{H}+18 \mathrm{O}_{\text {ads }} \mathrm{H}+\underset{\text { (4) }}{18 \mathrm{Al}_{\mathrm{i}}}
$$

The authors ${ }^{11)}$ also stated that the ultimate structure of the heavily hydrated surface is clearly very complicated and may depend strongly on sample history. It is also possible that the $\mathrm{Al}(\mathrm{OH})_{3}$ species can be removed completely (perhaps starting near steps or other defects), leaving a less reactive surface that is completely $\mathrm{O}_{\mathrm{s}} \mathrm{H}$ terminated, which is similar to the known surfaces of aluminum hydroxides. Wittbrodt et al. ${ }^{9)}$ also stated that under appropriate circumstances, removal of surface aluminum atoms to form a hydroxylated oxygen terminated surface is possible.

In this regard, Hass et al. ${ }^{11)}$ also applied room tempera- 
ture MD simulations of the idealized model of Nygren et al. ${ }^{10)}$ for a fully hydroxylated oxygen terminated $\alpha-\mathrm{Al}_{2} \mathrm{O}_{3}$ (0001) surface. Replacement of each surface Al with three $\mathrm{H}$ atoms yields a coverage of $>15 \mathrm{OH}$ per square nanometer. The simulation revealed a complex dynamic structure, with one of every three $\mathrm{OH}$ groups, on average, lying parallel to the surface because of in-plane hydrogen bonding. Calculated $\mathrm{O}-\mathrm{H}$ vibrational spectra yielded two broad peaks at 3470 and $3650 \mathrm{~cm}^{-1}$, with the $3470 \mathrm{~cm}^{-1}$ peak corresponding to in-plane hydrogen bonded $\mathrm{OH}$ groups.

The surface hydration state of sub-micron, commercially available, high purity, $\alpha$-alumina powders has been previously reported.12) It was shown in this study that the degree of surface hydration was different among the $\alpha$-alumina powders investigated, some of them exhibiting trihydroxide like bands in their infrared spectra and the $3470 \mathrm{~cm}^{-1}$ band predicted by Hass et al. ${ }^{11}$, for the fully hydroxylated $\alpha$ $\mathrm{Al}_{2} \mathrm{O}_{3}$ (0001) surface proposed by Nygren et al.. ${ }^{10)}$ Similar bands have been also observed in the spectra of as-received $\alpha$-alumina powders produced by the Bayer process. ${ }^{13), 14)}$ From calculated energies of water desorption, Nygren et al. ${ }^{10)}$ stated that the hydroxide layer should be thought of as the regular surface rather than a hydroxide adlayer.

In order to study the nature of the trihydroxide like bands observed in the infrared spectra of some as-received $\alpha-\mathrm{Al}_{2} \mathrm{O}_{3}$ powders produced by the hydrolysis of aluminum alkoxide method previously reported, ${ }^{12)}$ one of the powders is thermally hydrated. The characteristics of the hydrated powder are investigated by means of FTIR spectroscopy, XRD, as well as SEM and TEM observations. Changes in particle size distribution and specific surface area are also monitored.

\section{Experimental}

A high-purity, sub-micron $\alpha$-alumina powder (AKP-30, Sumitomo Chem.) produced by the hydrolysis of alkoxide method is used for evaluation in this work. The same powder was investigated in a previous study, with codification B2a. ${ }^{12)}$ The characteristics of the powder as reported by the manufacturer have been presented elsewhere. ${ }^{12), 15)}$ The powder was manufactured in 1997 and the FTIR measurements were performed in 1998. The hydration process is conducted by placing the alumina powder, without contact with water, in a modified pressure cooker heated inside an oven at $100^{\circ} \mathrm{C}$ under water saturated pressure, to produce a hydrothermal reaction on the powder surface. A schematic representation of the hydrothermal system is shown in Fig. 1. The hydrothermal process is conducted for a time period of $100 \mathrm{~h}$.

The as-received and the $100 \mathrm{~h}$ hydrated powders are separated into two fractions of different particle size by using a

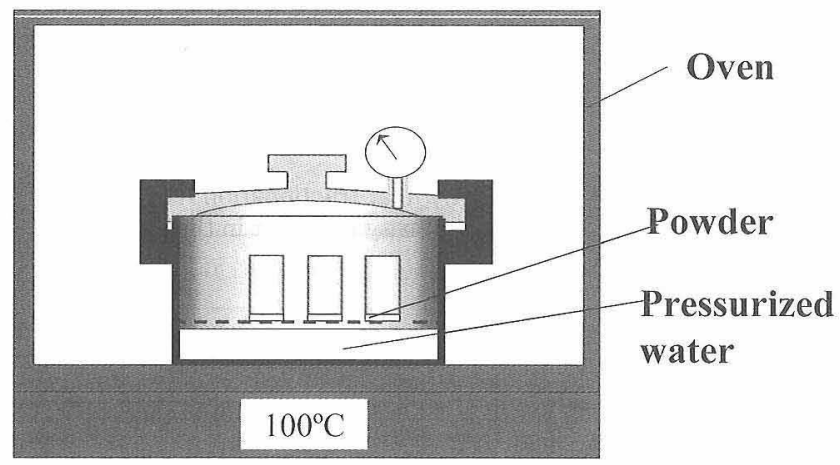

Fig. 1. Schematic of the hydorthermal process. centrifugal method at $1000 \mathrm{rpm}$ and $2000 \mathrm{rpm}$ of rotation speed. Slurries with concentration of $20 \mathrm{~g} / 1$ were prepared by dispersing $1 \mathrm{~g}$ of powder into $50 \mathrm{ml}$ of deionized water. The resulting mixtures are stirred for $5 \mathrm{~min}$, and then 28 $\mathrm{kHz} 135 \mathrm{~W}$ ultrasonic agitation was applied for $10 \mathrm{~min}$. The colloidal dispersed slurry was centrifuged in $10 \mathrm{ml}$ glass tubes for $15 \mathrm{~min}$ at $1000 \mathrm{rpm}$. This centrifugal condition allowed particles larger than $0.7 \mu \mathrm{m}$ to settle down completely. ${ }^{4)}$ The resulting supernatant, which contains only fine particles, is centrifuged again for $18 \mathrm{~min}$ at 2000 rpm. After drying the sediment at room temperature, FTIR, SEM and XRD analyses are conducted.

Grain size distribution and specific surface area of the powder before centrifuged are also evaluated. The grain size distribution measurements were conducted with a Shimadzu SA-CP3, using gravitational and centrifugal sedimentation method. Specific surface area is determined by the BET adsorption method with Shimadzu Flow Sorb 2300 equipment.

Diffused reflectance infrared Fourier transform (DRIFT) spectra are obtained by using Shimadzu FTIR 8000 spectrometer equipped with a Spectra-Tech diffuse reflectance accessory. The investigated powder was placed in a micro sample holder without diluting with $\mathrm{KBr}$. Each spectrum was scanned for 200 times with resolution of $4 \mathrm{~cm}^{-1}$. For background of the signal, an aluminum mirror is used.

To compare the results of structural infrared analyses, observations of the crystalline structure after powder separation are conducted by measurements of XRD patterns using Shimadzu XRD 6000. Scanning electron microscope (SEM) photographs of the powders are taken by using ELIONIX ESM 3200 equipment. Observation by TEM is conducted by using a JEOL 2010 electron microscope operated at 200 $\mathrm{kV}$.

\section{Results and discussion}

DRIFT spectra of the as-received alumina powder and the fractions separated by centrifugal method are shown in Fig. 2(a). Figure 2(b) shows the same powder after hydration for $100 \mathrm{~h}$ and the separated fractions. The wave numbers and assignment of the different bands observed in the spectrum of the as-received $\alpha$-alumina powder have been presented elsewhere. ${ }^{12)}$ Except for a prominent band at $3472 \mathrm{~cm}^{-1}$ all the other bands correspond to a mixture of aluminum trihydroxide polymorphs bands, namely bayerite, gibbsite and norstrandite. The low intensity aluminum trihydroxide polymorphs bands observed in the as-received powder increased by the hydration process but the intensity of the $3472 \mathrm{~cm}^{-1}$ band did not increase in the same proportion as seen in Fig. 2. It is observed that the relative intensity of the $3472 \mathrm{~cm}^{-1}$ band to the trihydroxide bands is larger in the as-received powder both before fractionation and in all the fractions after separation. For, the as-received as well as the hydrated product, the trihydroxide bands and the $3472 \mathrm{~cm}^{-1}$ band are more intense in the spectra of the large (1000 rpm) particle fractions. On the other hand, the infrared spectra of the as-received as well as the hydrated powder small $(2000 \mathrm{rpm})$ particle size fractions, show more intense absorption in the $3400-2700 \mathrm{~cm}^{-1}$ range. Comparing the spectra of the powders before fractionation, the absorbance in this range is higher in the spectrum of the asreceived powder. Similar broad tails are observed in the spectra of bayerite containing some boehmite. ${ }^{16)}$ Boehmite spectrum has bands around 3280 and $3090 \mathrm{~cm}^{-1}$. 17) Therefore, the broad peak in the spectra of the small particle size powders may be associated with monohydride like structures such as boehmite.

From the results discussed so far, it is clear that the trihydroxide like bands are mainly associated with the large 


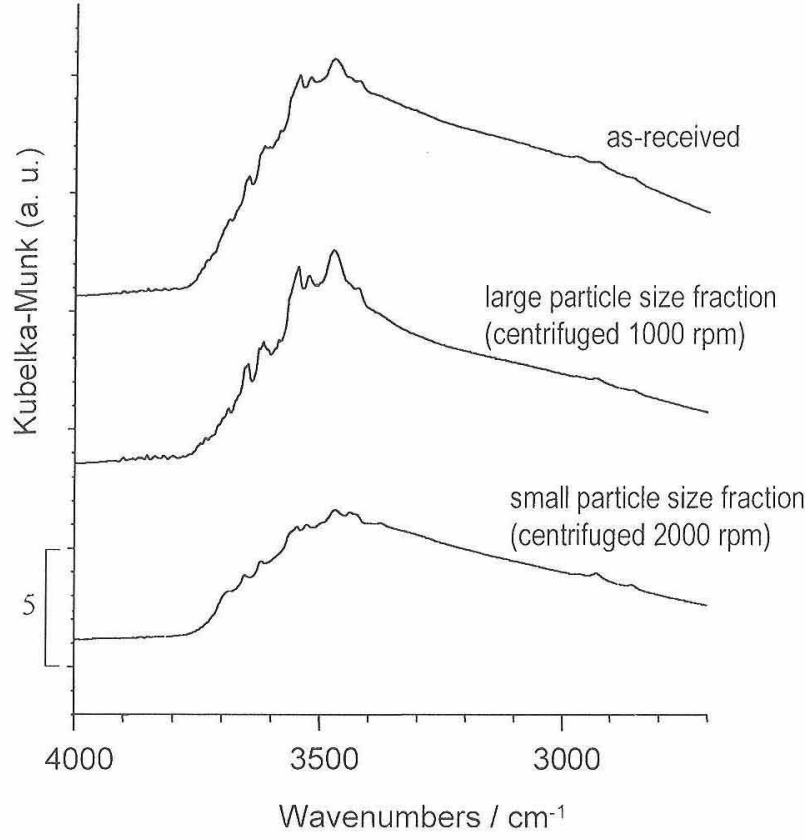

(a)

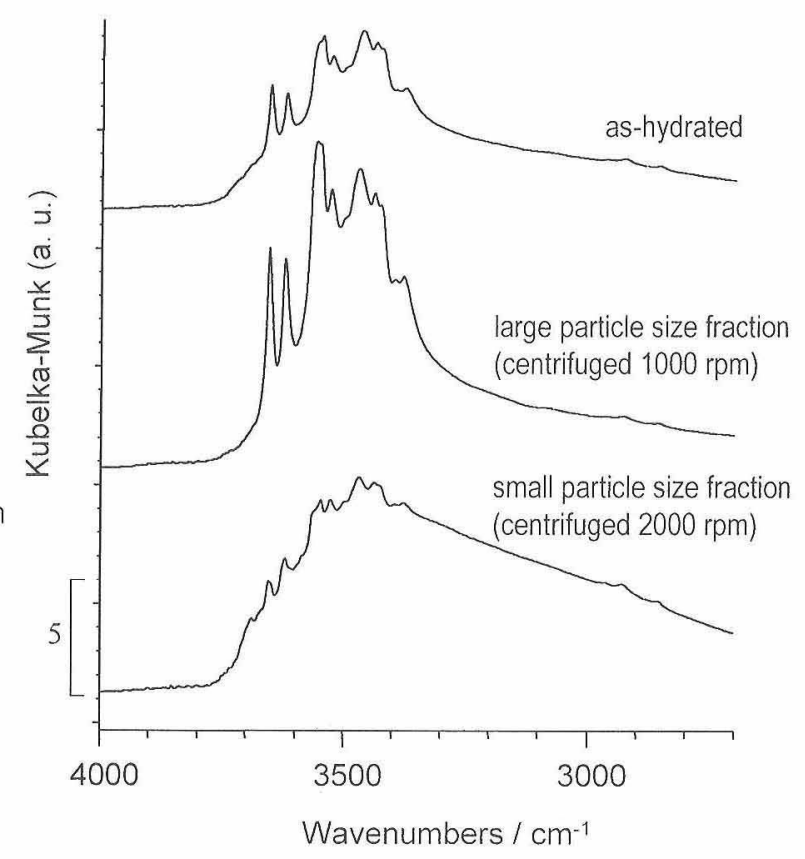

(b)

Fig. 2. Hydroxyl stretching absorption frequency region DRIFT spectra of powders before and after centrifugal fractionation. (a) asreceived $\alpha$-alumina powder B2a and (b) B2a powder thermally hydrated for $100 \mathrm{~h}$. The large particle size fractions show higher intensity aluminum trihydroxide polymorphs bands.

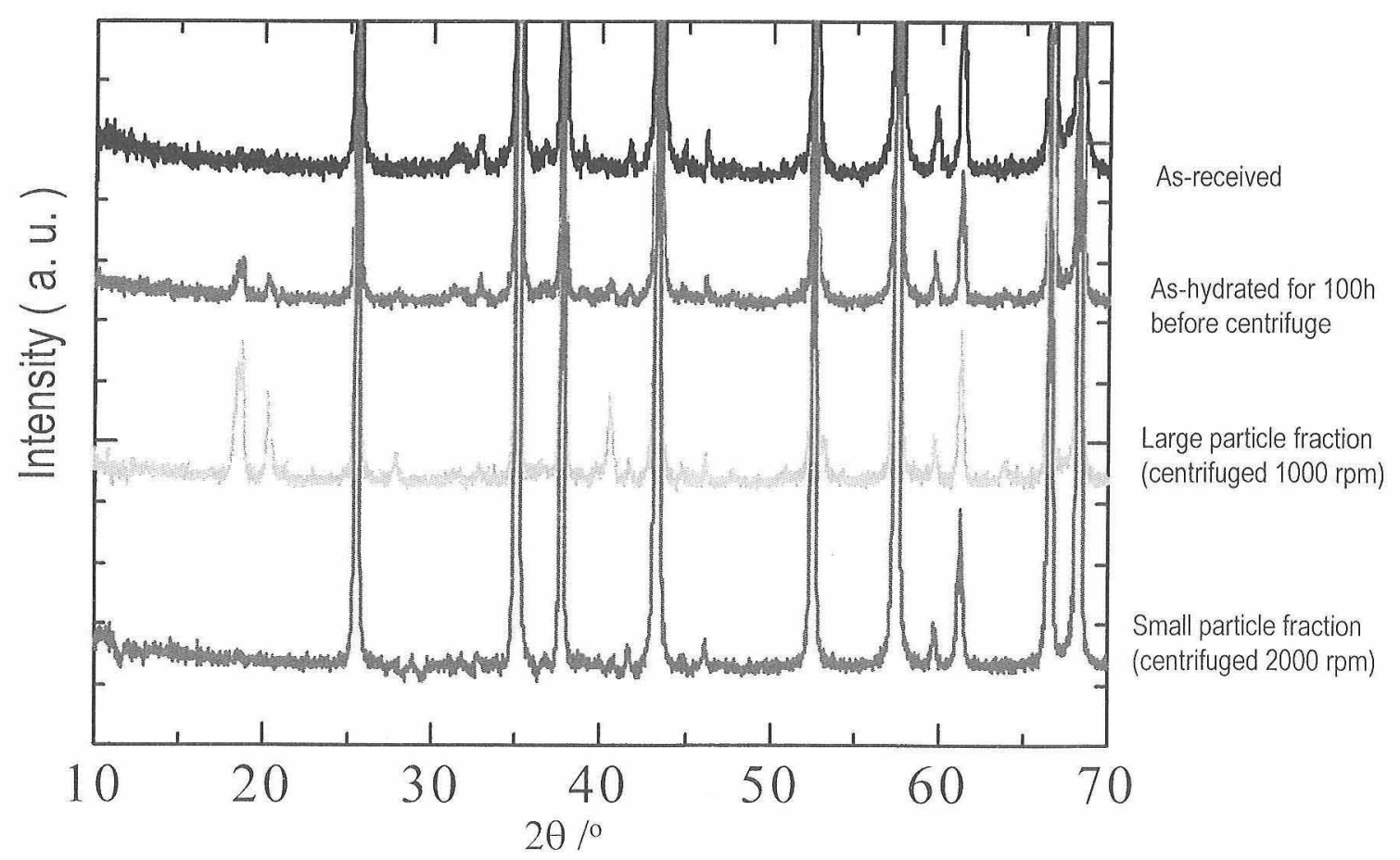

Fig. 3. XRD patterns of $\alpha$-alumina powder B2a thermally hydrated for $100 \mathrm{~h}$ before and after centrifugal fractionation. Aluminum trihydroxide polymorph diffraction peaks could be detected. In agreement with the DRIFT spectra, the intensity is higher in the large particle size fraction.

particle size fraction of the powders both before and after hydration. It is also clear that the hydration process has enhanced the formation of trihydroxide like structures. The large particle fraction of the hydrated powder was about $50 \%$ of the total, meanwhile in the case of the as-received powder it was very small (less than 5\%).

XRD patterns of the hydrated powder and the separated fractions were obtained and the results are shown in Fig. 3. 
Additional small diffraction peaks were detected in the hydrated powder before fractionation and in the large particle size $(1000 \mathrm{rpm})$ fraction. On the other hand, almost no aluminum trihydroxide peaks are detected in the XRD pattern of the small particle size fraction. The angles and intensities recorded for the $1000 \mathrm{rpm}$ fraction are listed in Table 1 together with the main diffraction peaks reported for aluminum trihydroxide polymorphs. The XRD results are in agreement with FTIR results showing a mixture of trihydroxide polymorphs as discussed in the previous report for the as-received powder. ${ }^{12)}$ In the case of the as-received powder the particles are concentrated in the small size $(2000 \mathrm{rpm})$ fraction and the amount of large size (1000 $\mathrm{rpm}$ ) particles fraction was not enough for XRD evaluation.

The generation of large size particles by the hydration process as shown in the above results is in agreement with the results of particle size distribution and SEM observations. Figure 4 shows the particle size distribution of the as-

Table 1. X-ray Diffraction Data for Aluminum Hydroxide Polymorphs ${ }^{18)}$ and $\alpha$-Alumina (B2a Powder) Thermally Hydrated for $100 \mathrm{~h}$

\begin{tabular}{|c|c|c|c|c|c|c|c|c|c|}
\hline \multicolumn{2}{|c|}{ Gibbsite } & \multicolumn{2}{c|}{ Bayerite } & \multicolumn{2}{c|}{ Nordstrandite } & \multicolumn{2}{c|}{$\begin{array}{c}\text { Bayer/ } \\
\text { Nordstrandite }\end{array}$} & \multicolumn{2}{c|}{$\begin{array}{c}\text { Hydrated } \\
\text { B2a Powder }\end{array}$} \\
\hline $\mathrm{d}(\mathrm{nm})$ & $\mathrm{I}$ & $\mathrm{d} \mathrm{nmA})$ & $\mathrm{I}$ & $\mathrm{d}(\mathrm{nm})$ & $\mathrm{I}$ & $\mathrm{d}(\mathrm{nm})$ & $\mathrm{I}$ & $\mathrm{d}(\mathrm{nm})$ & $\mathrm{I}\left({ }^{*}\right)$ \\
\hline 0.485 & 100 & & & & & & & 0.485 & 3 \\
\hline & & & & 0.479 & 100 & 0.477 & 100 & 0.48 & 5 \\
\hline & & 0.471 & 100 & & & 0.472 & 85 & 0.473 & 7 \\
\hline & & & & & & 0.436 & 100 & 0.438 & 4 \\
\hline & & & & & & & & 0.257 & 4 \\
\hline & & & & & & 0.222 & 100 & 0.222 & 3 \\
\hline
\end{tabular}

$\left.{ }^{*}\right)$ Intensities normalized with $\alpha$-alumina reflections.

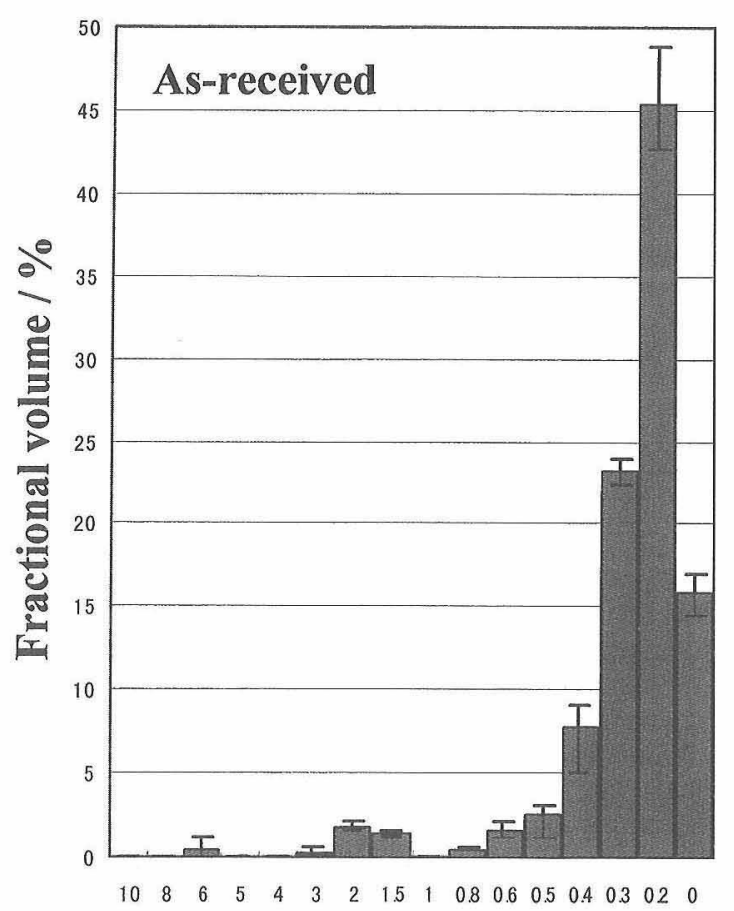

hydrated powder compared to the as-received powder. After hydration, the powder has high fraction of large particles between $0.5-0.8 \mu \mathrm{m}$. The particle size fractions of 0.2 and $0.3 \mu \mathrm{m}$, on the contrary, decreased and became lower than the as-received powder. Results of specific surface area measurement by BET one point method, show a $5 \%$ reduction; from $9.4 \mathrm{~m}^{2} / \mathrm{g}$ for the as-received powder to $8.9 \mathrm{~m}^{2} / \mathrm{g}$ for the hydrated powder. This is in agreement with the observed change in particle size distribution shown in Fig. 4. Results of SEM observations of as-received, and hydrated powders are shown in Fig. 5. Figure 5(a) corresponds to the as-received powder meanwhile, (b) and (c) are micrographs of the large (1000 rpm) and small (2000 rpm) particle size fractions of the hydrated powder, respectively. Figure 5(d) is an enlargement of a particle from Fig. 5(b). Large particles are significantly found in the hydrated powder. SEM photographs clearly show that hydration of the surface has promoted formation of hard agglomerates, in which the particles are cemented together by the hydrated phase. Typical transmission electron micrographs of the asreceived and hydrated $\alpha$-alumina powders are presented in Figs. 6(a), 6(b), 6(c) and 6(d). The observed average particle size of these powders is between $0.2-0.3 \mu \mathrm{m}$, which is in accord with the particle size distribution of the asreceived $\alpha$-alumina powder shown in Fig. 4. As seen in Fig. 6 (c), the thermally hydrated $\alpha$-alumina powder consists of agglomerated individual particles of the same size as the asreceived powder. The TEM observations revealed that the agglomeration of $\alpha$-alumina particles is enhanced by hydration; the sticking of particles occurs at the interface between two adjacent particles in which an existing surface layer seems to play an important role.

As shown in Fig. 2 (a), the fraction of the particles after

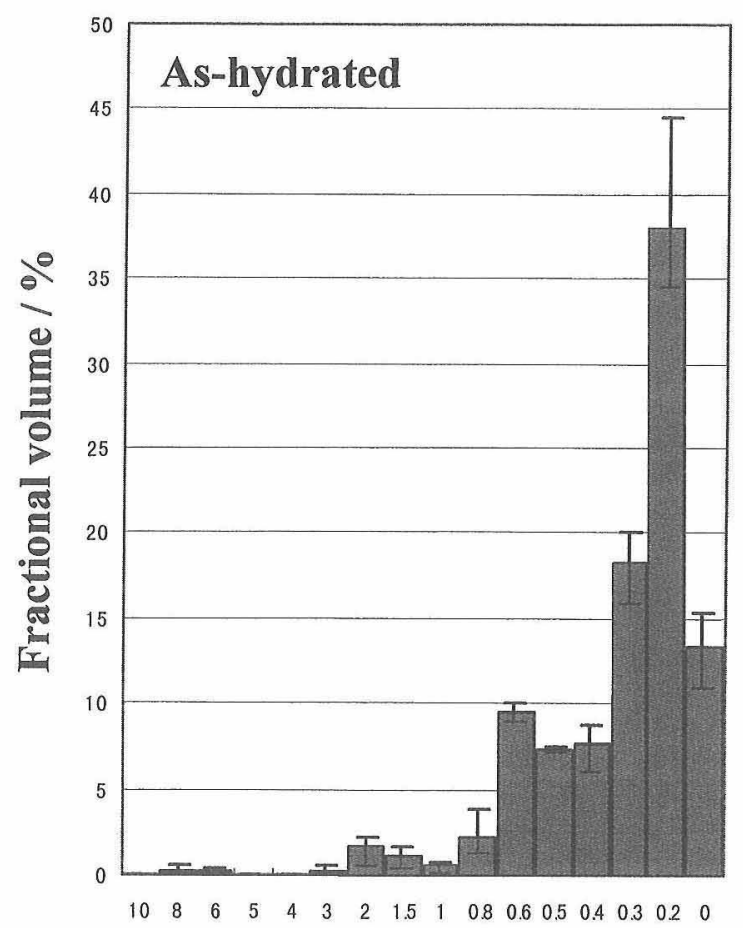

\section{Particle size / $\mu \mathrm{m}$}

Fig. 4. Particle size distribution of as-received $\alpha$-alumina powder B2a and the same powder after being thermally hydrated for $100 \mathrm{~h}$. After hydration, the powder has high fraction of large particles between $0.5-0.8 \mu \mathrm{m}$. The particle size fractions of $0.2-0.3 \mu \mathrm{m}$, on the contrary, decreased and became lower than the as-received powder. 


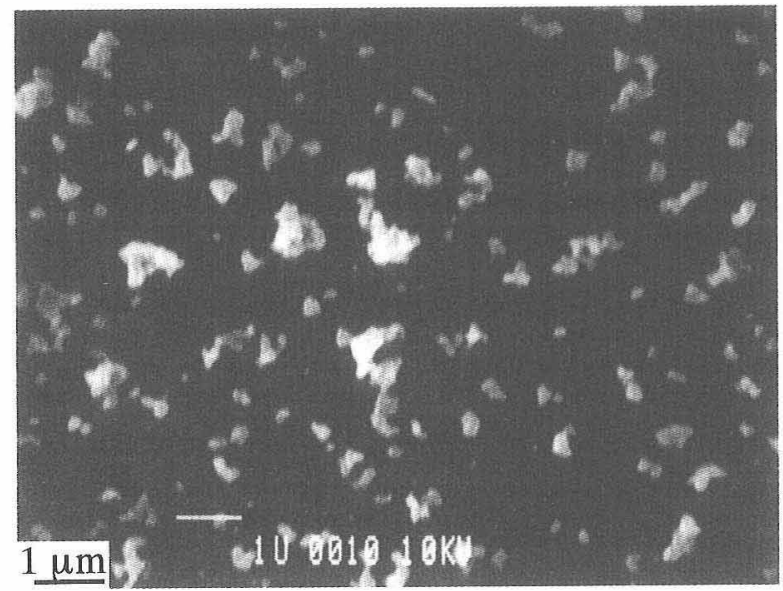

(a)

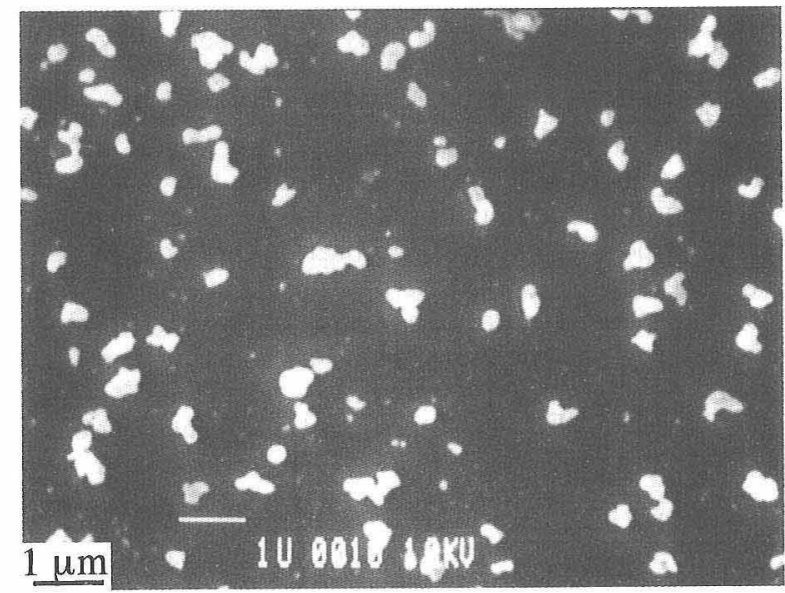

(c)

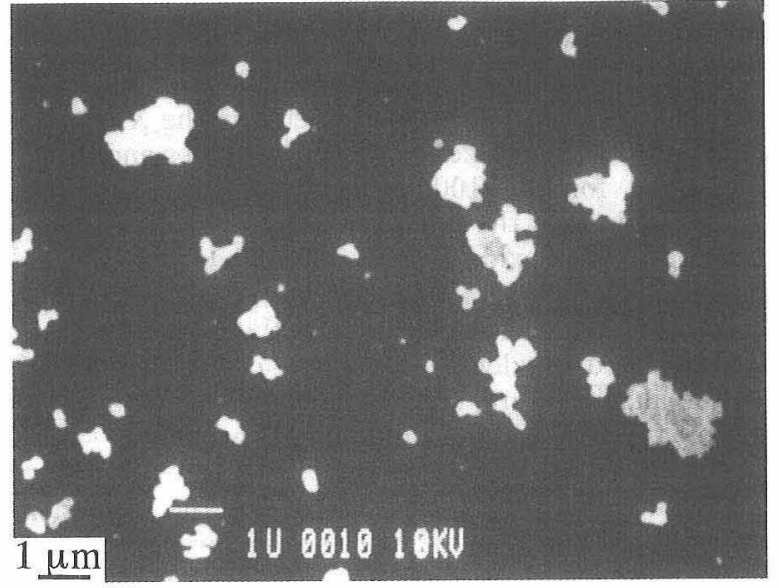

(b)

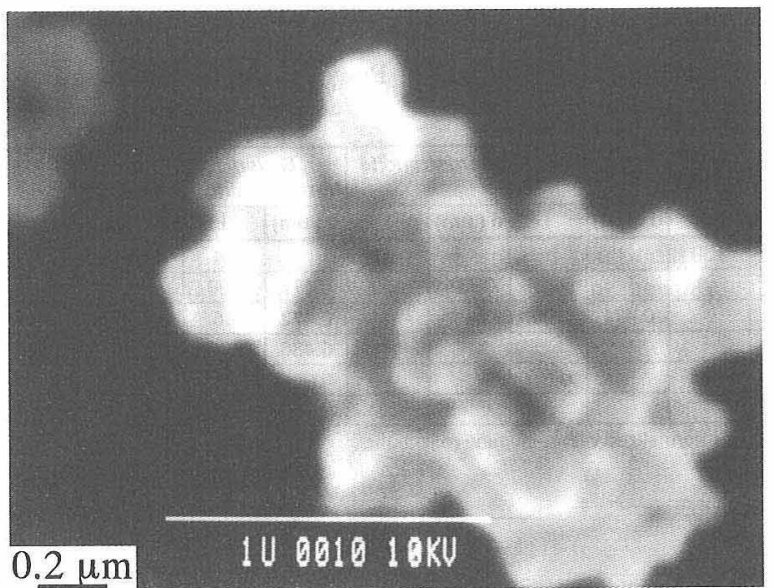

(d)

Fig. 5. SEM micrographs of as-received $\alpha$-alumina powder B2a (a), large (b) and small (c) particle size centrifugal fractions of the same powder after being thermally hydrated for $100 \mathrm{~h}$ and, (d) magnified image of hard agglomerate within the large particle size fraction micrograph (b).

centrifuged at $1000 \mathrm{rpm}$ has more significant trihydroxides bands and in the SEM photograph of the as-received powder, Fig. 5(a), some hard agglomerates can be observed. Also the TEM observation in Figs 6(a) and (b) clearly show interconnection of particles in the as-received powder. These results show that hard agglomerates have been produced between high-purity $\alpha$-alumina particles even under atmospheric conditions.

The findings of the present work are in agreement with the predictions made by Hass et al. ${ }^{11)}$ up to the possible level and nature of $\alpha$-alumina surface hydration at $25^{\circ} \mathrm{C}$, as shown in Eq. (4) of the introduction, but go even further in showing that the surface $\mathrm{Al}(\mathrm{OH})_{3}$ structures of adjacent particles can join together by hydrogen bonding creating crystalline structures similar to the aluminum trihydroxide polymorphs.

It has long been recognized that ceramic powders prone to hydration can form agglomerates in which the particles are cemented together by a hydrated phase. ${ }^{19)}$ However, the formation mechanism in the case of aluminas has been mainly associated with dissolution-precipitation processes when the powders are milled in the presence of water ${ }^{3)}$ or col- loidally dispersed and classified in water. ${ }^{4)}$ Furthermore, Kitayama and Pask ${ }^{4)}$ interpreted the formation of hard agglomerates in the water classified high-purity $\alpha$-alumina powder to be associated with transition aluminas present in the powder.

So far our knowledge this is the first time that a possible different mechanism for the formation of hard agglomerates in $\alpha$-alumina powders has been proposed. This mechanism can also explain the presence of hard agglomerates even in as-received high-purity $\alpha$-alumina powders without intervention of transition phases.

\section{Conclusions}

A high-purity, sub-micron, $\alpha$-alumina powder produced by the hydrolysis of aluminum alkoxide method and a thermally hydrated product of the as-received powder have been investigated. The powders were separated into two particle size range fractions by a centrifugal method. The DRIFT spectra show enhancement of bands associated with aluminum trihydroxide polymorphs and in-plane hydrogen bonded hydroxyls by the hydrothermal process. After fractionation, the intensity of these bands is larger in the large parti- 


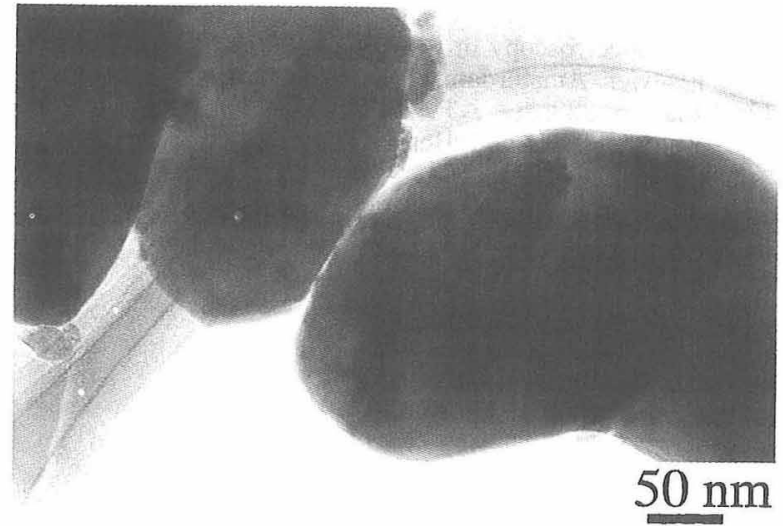

(a)

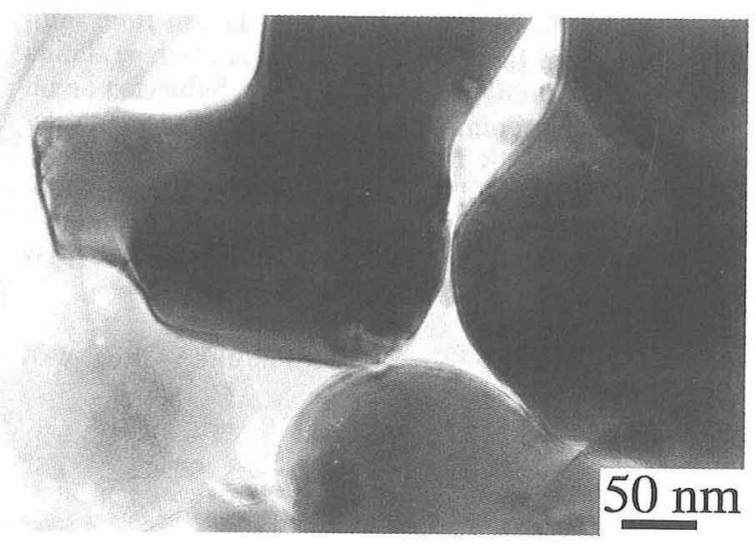

(c)

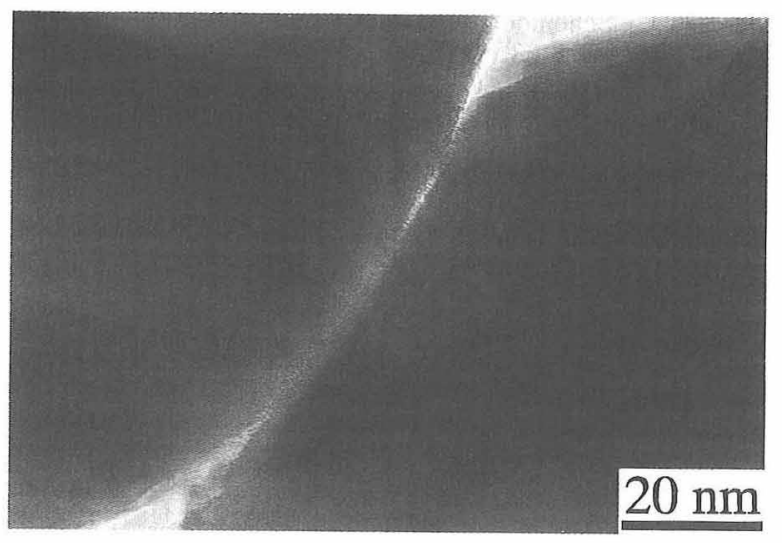

(b)

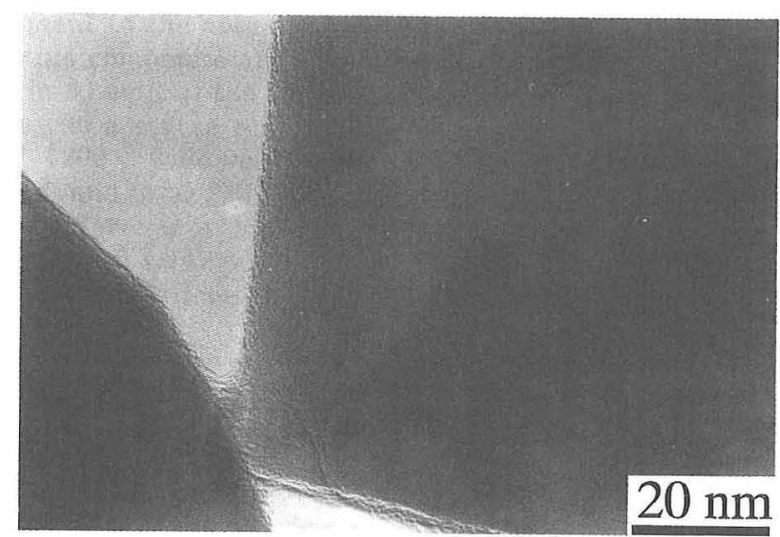

(d)

Fig. 6. Transmission electron micrographs for (a), (b) as-received $\alpha$-alumina powder B2a and (c), (d) the same powder thermally hydrated for $100 \mathrm{~h}$. Particles sticking each other are seen in the as-received and thermally hydrated conditions.

cle size fractions of the as-received, as well as the hydrated product. The amount of aluminum trihydroxide polymorphs in the hydrated powder was large enough to be detected in the XRD pattern of the powder. Particle size distribution measurements indicate a reduction of $0.2-0.3 \mu \mathrm{m}$ and increase of $0.5-0.8 \mu \mathrm{m}$ size particles in the hydrated with respect to the as-received powder, with a concomitant decrease in specific surface area of 5\%. SEM observation of the powders shows the presence of large agglomerates in the hydrated powder. In a lesser extend, agglomerates are also noticeable in the as-received powder. TEM images of the as-received and hydrated alumina powders revealed the presence of a surface layer interconnecting two $\alpha$-alumina particles. From all these results, it is concluded that the surface of the high-purity, sub-micron, $\alpha$-alumina powder investigated followed the hydration pattern predicted by Hass et al. ${ }^{11)}$ with formation of surface $\mathrm{Al}(\mathrm{OH})_{3}$ structures. Furthermore, it is concluded that $\mathrm{Al}(\mathrm{OH})_{3}$ surface structures of adjacent particles can form hydrogen bonding creating crystalline structures similar to the aluminum trihydroxide polymorphs. These structures are believed to be responsible for hard agglomerate formation even in the as-received alumina powder.

Acknowledgements The authors are grateful to ITAC Ltd. for financial support to P. R. during this research. We also thank
Sumitomo Chemical Co., Ltd. for supplying the powder, and Ms. Megumi Okasaki for the particle size distribution measurements.

\section{References}

1) Wefers, K. and Misra, C., "Oxides and Hydroxides of Aluminum," Alcoa Technical Paper No. 19, Revised, Alcoa Laboratories, Aluminum Company of America, Pittsburgh (1987) p. 18.

2) Tamura, Y., Sumitomo Chemical Co., Ltd., Alumina Product and Composite Materials Dept., Personal Communication (1998).

3) Niesz, D. E. and Bennett, R. B., "Ceramic Processing Before Firing," Ed. by Onoda, Jr., G. Y. and Hench, L. L., Wiley, New York (1978) pp. 61-74.

4) Kitayama, M. and Pask, J. A., J. Am. Ceram. Soc., 79, 2003-11 (1996).

5) Morterra, C., Ghiotti, G., Garrone, E. and Boccuzzi, F., J. Chem. Soc., 72, 2722-34 (1976).

6) Schildbach, M. A. and Hamza, A. V., Surface Science, 282, 306-22 (1993).

7) Elam, J. W., Nelson, C. E., Cameron, M. A., Tolbert, M. A. and George, S. M., J. Phys. Chem. B, 102, 7008-15 (1998).

8) Nelson, C. E., Elam, J. W., Cameron, M. A., Tolbert, M. A. and George, S. M., Surface Science, 416, 341-53 (1998).

9) Wittbrodt, J. M., Hase, W. L. and Schlegel, H. B., J. Phys. Chem. B, 102, 6539-48 (1998).

10) Nygren, M. A., Gay, D. H. and Catlow, C. R. A., Surface Science, 380, 113-23 (1997). 
11) Hass, K. C., Schenider, W. F., Curioni, A. and Andreoni, W., Science, 282, 265-68 (1998).

12) Raharjo, P., Ishizaki, Ch. and Ishizaki, K., J. Ceram. Soc. Japan, 108, 449-55 (2000)

13) Lee, D. H. and Condrate Sr., R. A., Mater. Lett., 23, 241-46 (1995).

14) Incorvati, C. M., Lee, D. H., Reed, J. S. and Condrate Sr., R. A., Am. Ceram. Soc. Bull., 76, 65-68 (1997).

15) Raharjo, P., Ishizaki, Ch. and Ishizaki, K., J. Ceram. Soc. Japan, 108, 1-5 (2000).
16) van der Marel, H. W. and Beutelspacher, H., "Atlas of Infrared Spectroscopy of Clay Minerals and Their Admixtures," Elsevier, Amsterdam (1976) p. 226

17) Ibid., p. 228.

18) Elderfield, H. and Hem, J. D., Mineral. Mag., 39, 89-96 (1973).

19) Halloran, J. W., "Ultrastructure Procesing of Ceramics, Glass and Composites," Ed. by Hench, L. L. and Ulrich, D. R., Wiley, New York (1984) p. 406. 